\title{
Infantile multiple large pyogenic granuloma on burned skin. Case report and review of literature*
}

\author{
Ladan Dastgheib ${ }^{1}$ \\ Fatemeh Sari Aslani ${ }^{1}$
}

\author{
Zohreh Maghami $^{1}$
}

DOI: http:/ / dx.doi.org/10.1590/abd1806-4841.20164060

\begin{abstract}
Pyogenic granuloma (PG) is a benign vascular lesion of the skin and mucous membranes, presenting as a solitary, red, pedunculated papule that bleeds easily and which appears to be a reactive vascular proliferation to minor injury. These lesions are more common in children and are mostly seen in exposed sites. Multiple disseminated PG is a rare condition. This report describes an infant with multiple, disseminated, pyogenic granulomas following burns from boiling milk. We reviewed literature published in English and found 9 cases. Six cases were provoked by hot milk, 2 by hot water, while the cause of the other case is unknown. Angiogiogenetic activity in milk may explain PG development in these patients.
\end{abstract}

Keywords: Burns; Granuloma, pyogenic; Milk

\section{INTRODUTION}

Pyogenic granuloma (PG) is a common, benign, acquired vascular lesion of the skin and mucous membranes. It generally appears as a solitary, red nodule on the face, trunk and limbs, mostly among the pediatric age group. Although the underlying cause is not well-understood, minor trauma, chronic irritation, hormonal factors, viral infections and drugs are considered etiologic factors. It is known as a reactive vascular proliferation, rather than a true neoplasia. ${ }^{1-2} \mathrm{Few}$ case reports of multiple disseminated PG in the published literature describe post-generalized traumas such as scald burns. ${ }^{1-6}$

\section{CASE REPORT}

A 12- month-old infant boy was referred by the Ghotb-e-din burn unit to our department, following sudden development of multiple, red, papules and nodules on the periphery of healing second-degree burn sites on the bilateral lower limbs. The patient was playing near an oven when he was burned by boiling milk. He was admitted to a burn care center and received intravenous antibiotics, undergoing daily dressing with silver sulfadiazine. Two weeks later, when the burn lesions were healing, multiple eruptive, red lesions were noted on the periphery of burn sites on both legs (Figures 1-2). These new lesions bled eas- 


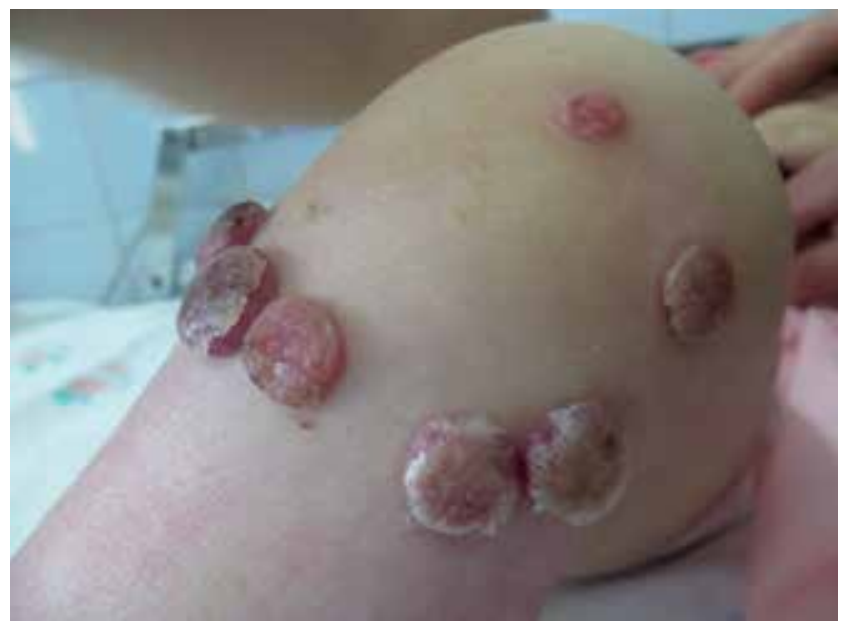

Figure 1: Multiple erythematous pedunculated nodules around burn scar on knee

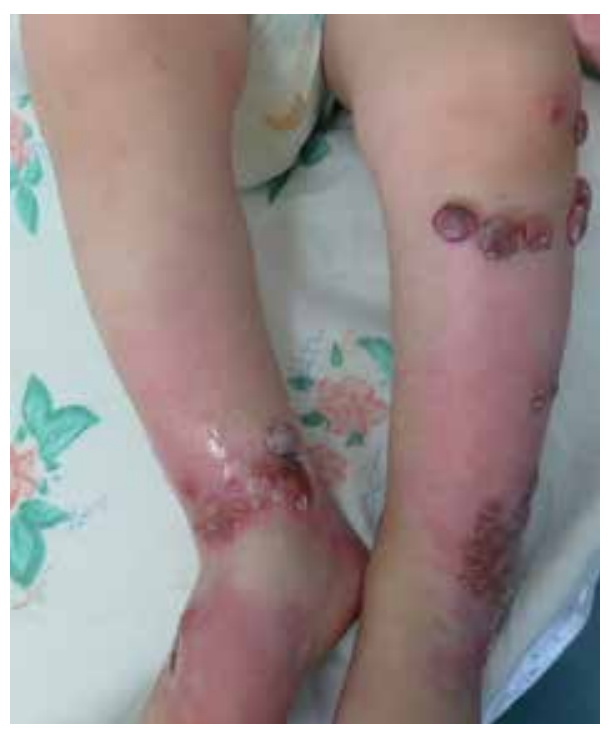

FIGURE 2:

Numerous red papules on burn scar on shins

ily with minor trauma. The patient was observed for another 2 weeks and treated using dressing with silver sulfadiazine, to no avail. Furthermore, the physical examination revealed multiple, erythematous, pedunculated papules and nodules on the knees and shins. They varied in size the largest measuring $2.5 \times 2.5 \mathrm{~cm}$.

A biopsy showed an intact epidermis with underlying proliferation of capillary-sized blood vessels in a edematous stroma. The histologic picture of this superficial biopsy may be consistent with the clinical diagnosis of pyogenic granuloma (Figures 3-4).

Unfortunately, the patient was lost to follow-up.

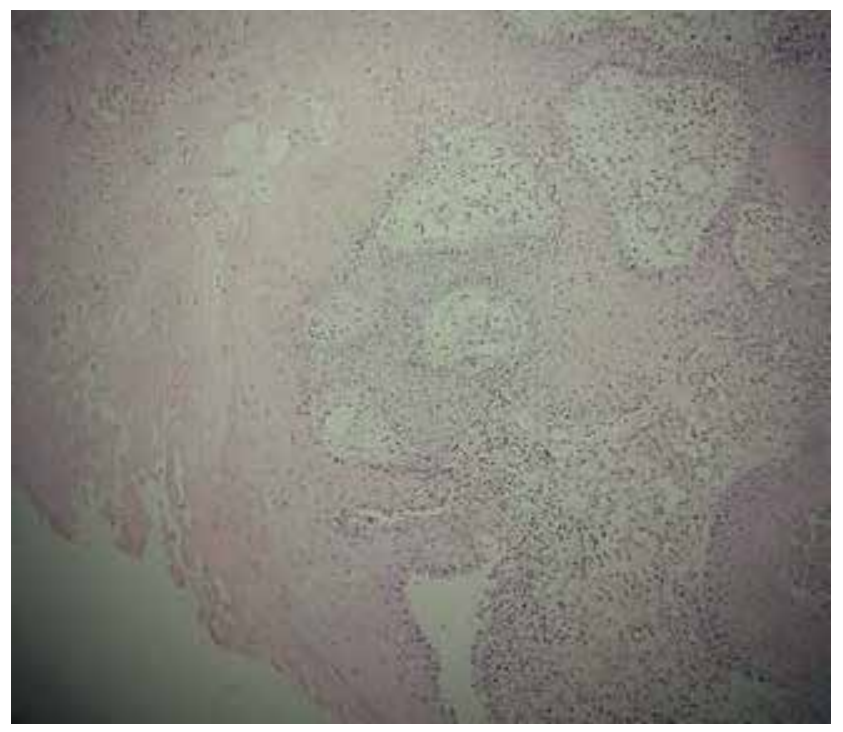

FIGURE 3: Histopathologic image of lesion

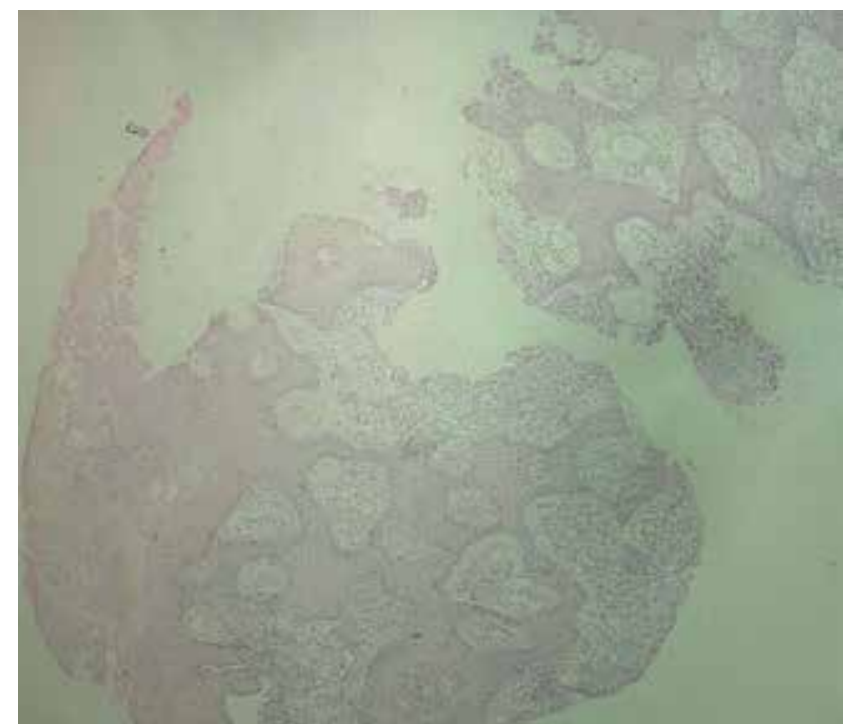

FIGURE 4: Histopathologic image of lesion

\section{DISCUSSION}

PG, also known as lobular capillary hemangioma, was first described in 1987 by Poncent and Dore. The pathogenesis remains unclear and many factors including trauma, infection, increased level of female sex hormones (pregnancy), viral oncogenes, microscopic arteriovenous anastomoses and growth factors, may play a role. ${ }^{3}$

Differential diagnosis includes multiple benign and malignant conditions such as amelanotic melanoma, angiosarcoma, basal cell carcinoma, Kaposi sarcoma, hemangioma, bacillary angiomatosis, metastatic visceral malignancies and granulation tissue. ${ }^{4}$ 
CHART 1: Demographic data of reported post burn multiple eruptive pyogenic granulomas in the English literature

\begin{tabular}{|c|c|c|c|c|c|}
\hline Degree of burn & Site of burn & Causing agent & $\operatorname{sex}$ & Age (year) & \\
\hline Second & trunk & milk & female & 5 & Momeni et al, 1995 \\
\hline Second & trunk & milk & male & 18 & \\
\hline Second & trunk & milk & female & 35 & \\
\hline Second & Arm & water & male & 1.5 & Ceyhan et al, 2007 \\
\hline Second & Face, neck & unknown & female & 2 & Durgun et al, 2013 \\
\hline Second & Arm & water & Male & 7 & \\
\hline Second & Forearm & milk & male & 2 & Bozkurt et al, 2006 \\
\hline Second & Arm & milk & female & 18 & Ceyhan et al, 1997 \\
\hline Second & Arm & unknown & female & 5 & Aliagaoglu et al, 2006 \\
\hline
\end{tabular}

There are several methods for treating PG but recurrence is a major problem for patients. Options include: excision, electrocautery, $\mathrm{CO}_{2}$ laser and pulsed dye laser therapy. ${ }^{1}$

In the English-language literature, there were 9 rare cases of multiple, disseminated, eruptive PG occurring following scald burns. Six cases were provoked by hot milk, 2 hot water, while the cause of the other case is unknown (Chart). ${ }^{1-6}$

The time trend in the aforementioned cases was similar to that of our case: patients developed lesions within 2 weeks of suffering burns, all of which were second-degree. It appears to be no coincidence that most patients endured burns from milk, as the three others patients scalded by other hot liquids did not develop PG. Milk contains mainly water, protein, lipid, carbohydrate (lactose) and minerals. Although the exact mechanism remains to be understood, angiogiogenetic activity in milk may explain PG development in these patients. ${ }^{7,8}$

Importantly, all the reported cases are from Iran and Turkey, possibly due to the habit of boiling raw milk at home on stoves and not using pasteurized milk in urban areas. $]$

\section{REFERENCES}

1. Bozkurt M, Külahçi Y, Zor F, Aşkar I. multiple giant disseminated pyogenic granuloma in burn lesion. J Burn Care Res. 2006;27:247-9.

2. Momeni AZ, Enshaieh S, Sodifi M, Aminjawaheri M. Multiple giant disseminated pyogenic granuloma in three patients burned by boiling milk. Int J Dermatol. 1995;34:707-10.

3. Ceyhan AM, Basak PY, Akkaya VB, Yildirim M, Kapucuoglu N. A case of multiple, eruptive pyogenic granuloma developed on a region of burned skin: can Erythromycin be a treatment option? J Burn Care Res. 2007;28:754-7.

4. Durgun M, Selçuk CT, Ozalp B, Aydinol M, Alabalik U. Multiple disseminated pyogenic granuloma after second degree scald burn: a rare two case. Int J Burns Trauma. 2013;3:125-9.

5. Aliağaoğlu C, Bakan V, Atasoy M, Toker S. Pyogenic granuloma with multiple and satellite involvement after a burn in 5 years old child. J Dermatol. 2006;33:150-2. Ceyhan M, Erdem G, Kotiloğlu E, Kale G, Talim B, Kanra G, et al. Pyogenic granuloma wiyh multiple dissemination in a burn lesion. Pediatr Dermatol. 1997;14:213-5.

7. Pavlov N, Badet J. Angiogenin: involvement in angiogenesis and tumour growth. Bull Cancer. 2001;88:725-32.

8. Komolova GS, Fedorova TV.Milk angiogenin (Review). Prikl Biokhim Mikrobiol. 2002;38:229-36.

\author{
MAILING ADDRESS: \\ Zohreh Maghami \\ Dermatology Department \\ School of medicine \\ Shiraz Universityof Medical Sciences \\ 7134675467 - Shiraz - Iran \\ E-mail:z_maghami7@yahoo.com
}

How to cite this article: Dastgheib L, Maghami Z, Sari Aslani F. Infantile multiple large pyogenic granuloma on burned skin. Case report and review of literature. An Bras Dermatol. 2016;91(2):212-4 